\title{
Movement and Song Idiom Traditional to Enhance Early Mathematical Skills: Gelantram Audio-visual Learning Media
}

\author{
Taufik Hidayatulloh ${ }^{1}$ \\ Universitas Negeri Jakarta, Indonesia ${ }^{1,2,3}$ \\ Elindra Yetti ${ }^{2}$ \\ Hapidin $^{3}$
}

DOI: https://doi.org/10.21009/JPUD.142.02

Accepted: August $15^{\text {th }}$ 2020.Approved: September $4^{\text {th }} 2020$. Published: $30^{\text {th }}$ November 2020

\begin{abstract}
Many studies have shown a link between being competent in early mathematics and achievement in school. Early math skills have the potential to be the best predictors of later performance in reading and mathematics. Movement and songs are activities that children like, making it easier for teachers to apply mathematical concepts through this method. This study aims to develop audio-visual learning media in the form of songs with a mixture of western and traditional musical idioms, accompanied by movements that represent some of the teaching of early mathematics concepts. The stages of developing the ADDIE model are the basis for launching new learning media products related to math and art, and also planting the nation's cultural arts from an early age. These instructional media products were analyzed by experts and tested for their effectiveness through experiments on five children aged 3-4 years. The qualitative data were analyzed using transcripts of field notes and observations and interpreted in a descriptive narrative. The quantitative data were analyzed using gain score statistics. The results showed that there was a significant increase in value for early mathematical understanding of the concepts of geometry, numbers and measurement through this learning medium. The results of the effectiveness test become the final basis of reference for revision and complement the shortcomings of this learning medium. Further research can be carried out to develop other mathematical concepts through motion and song learning media, and to create experiments with a wider sample.
\end{abstract}

Keywords: Early Mathematical Skills, Movement and Song Idiom Traditional, Audio-visual Learning Media

\footnotetext{
${ }^{1}$ Corresponding Author:

Universitas Negeri Jakarta

Email: taufikgibran87@gmail.com
} 


\section{INTRODUCTION}

The results of Indonesia's PISA data for mathematics and science are also a big homework. For Mathematics scores, it is ranked 72 out of 78 countries. The Science score is ranked 70 out of 78 countries. This value has tended to be stagnant in the last $10-15$ years (Harususilo, 2020). The low level of mathematics ability among students in Indonesia, in particular, requires important attention from various parties, such as teachers and parents. Often mathematics is disliked due to limited media and fun learning models, especially in children's learning. Therefore, it requires high creativity and innovation from educators and parents.

The low rank in the world with the math ability in Indonesian children, making most children anxious, afraid, and do not like mathematics. Some researchers say that math anxiety can be triggered by weak math skills, others argue that math anxiety exists at all math skill levels (Pantoja et al., 2020). In fact, the results of the study indicate the relationship between children's math anxiety and parental beliefs and attitudes. Parents with stronger beliefs about the importance of math tend to have children with higher math skills (Silver et al., 2020). Early math skills and knowledge are closely linked to long-term achievement, but there is little knowledge of the processes, forms of mathematical activity, and by which children acquire these skills and knowledge (Missall et al., 2015). To ensure children master the concepts of math skills necessary for success in the future, it is important to find or create a variety of media and learning methods that attract preschoolers to math and reduce math anxiety in school.

Poor math competence among adult's results in difficulties and difficulties at work in many common daily activities (Geary, 2012). Low performance in mathematics competence can be avoided by pursuing quality mathematics teaching in Early Childhood Education that understands its long-term benefits and does not just maintain access for all children (Bausela Herreras, 2017). Teachers and parents should give every child the opportunity to learn mathematics from an early age. However, as shown by many studies, the potential of individuals to excel in school is highly dependent on their math skills in school (Geary, 2011). Vennberg's et al., (2018) findings suggest that deliberate systematic learning of pre-school intervention programs will improve children's long-term success in mathematics. As well as learning models or the use of representations are needed in the process of planting early mathematical concepts, because an important aspect of mathematics is representation (Sterner et al., 2020). In fact, mathematicians use representations such as pictures, graphs, diagrams and simplified equations at all levels to analyze and communicate their work (Cross et al., 2009). Intervention through audio-visual media with content of images related to mathematical concepts can be a good representation tool for early childhood.

Fun interventions in early childhood usually involve movement and song. Moreno et al., (2011) mentioned the children in the music training group that showed increased intelligence and allowed the transfer of high-level cognitive skills in early childhood. Music interventions were found to be more effective than video game interventions at improving attention control in children (Kasuya-Ueba et al., 2020). The integrated music-math learning intervention led to a statistically significant increase in the math ability of children playing music (Roa \& IA, 2020). An and Tillman (2015) conducted a study to examine the effects of a sequence of class-room activities that integrate math content with musical elements, which aims to provide an alternative approach for teachers to teach mathematics. Interdisciplinary music-math lessons had beneficial effects on several areas of mathematical ability (S. An et al., 2013).

The current state of the pandemic encourages online early-childhood mathematics professional development programs and learning media related to technology developed to meet the needs of early-childhood educators (Sheridan et al., 2020). Early-childhood education experts in the field of ICT and mathematics from Greece revealed their findings that compared to conventional teaching approaches, tablet-assisted learning provides better learning outcomes for early childhood (Zaranis et al., 2013). Likewise, when comparing learning between the use of tablets and computers, the former makes a more significant contribution to the development of children's math abilities. Maybe because the use of tablets is simpler and easier to move and carry, more fun for children (Stamatis Papadakis et al., 2016). Intervention through audio-visual media that can be 
input into various digital devices will make it convenient for children to absorb many concepts of knowledge, especially for children who have felt a connection with technology since in the womb.

Previous research using songs to improve children's math skills, one of which is from Basco (2020), who has tested the learning media for song, drill and games in teaching mathematics and with the name Sodriga strategy, has shown cognitive improvement, motivation, and building constructive attitudes towards learning mathematics while increasing mastery and retention of the concepts. Based on research on mathematical skills, and related to movement and songs into children activities, as well as technological devices in the early-childhood classroom, this study aims to make a new product in learning media for introduce math concept through digital device. Movement and songs learning media were made to improve math skills in three early math concepts, namely the concepts of geometry, measurement, and numbers. This research will develop movement and songs learning media with traditional music idioms, in addition to improving math skills as well as introducing distinctive features of Indonesian culture Early childhood.

\section{THEORITICAL STUDY}

\subsection{The Importance of Early Mathematics Skills Competencies}

The significance of early mathematics interventions is attested by numerous studies on children's learning in the first six years of life (Sarama \& Clements, 2006b). For children's early experiences with mathematics, a fun and supportive atmosphere develops their confidence in their ability to understand and use mathematics. These positive experiences help children build settings that lead to their potential for success inside and outside of school, such as enthusiasm, creativity, versatility, inventiveness and determination (Sarama \& Clements, 2006a). During the preschool years, children's mathematics skills undergo comprehensive growth. However, opportunities to participate in mathematics in the preschool classroom are limited, and lessons and preparation are often aimed below the ability levels of children (Litkowski et al., 2020).

Internationally, children's poor math outcomes reflect the need for a new approach to teaching math concepts, one that differs from conventional approaches to learning and teaching mathematics (Papadakis et al., 2017). It is hoped that the Covid-19 pandemic will stimulate educators to be able to provide well-designed media, enrich, expand, and strengthen the mathematical knowledge of children they bring from home.

\subsubsection{Geometry}

Early childhood learning the name of geometric shapes beforehand is by the teacher showing various geometric shapes to preschoolers who initially have disaggregated knowledge. Verdine's et al., (2015) research investigates when children first begin to understand shape names and how they apply those labels to unusual examples. Comparing sample objects with geometric shape names will lead children to refine shape categories. Gejard and Melander (2018) explores the mathematics of preschool children in daily block play activities. Knowledge of children's use of geometric discourse appears in the flow of ongoing interactions. The opportunity to introduce geometric shapes to children will be greater when the learning media invites children's interest.

To develop spatial sensitivity, a child must have experiences that lead to geometrical relationships, namely direction, spatial orientation and point of view of objects in space, the size and shape of objects, and how shapes can change as a result of changes in size (Maričić \& Stamatović, 2017). The spatial sensitivity experience when children move and sing, along with the recognition of representative images in audio-visual media, allow more opportunities to improve children's spatial intelligence and children's mathematical abilities in understanding geometric shapes from an early age.

\subsubsection{Measurement}

Direct participation in measuring objects in class allows children to make their understanding of length measurements, and relates classroom learning to their own experiences in meaningful 
ways (Macdonald \& Lowrie, 2011). Teacher instructional actions at a specific level can be a means of promoting informal measurement theory (Barrett et al., 2011). It takes a special learning environment design to teach children about measurement, which is the development of flexible strategies and adaptive, depending on the use of mathematical structures.

\subsubsection{Numbers}

Children who reach pre-school with weaker mathematical language abilities are more likely to fail to learn numeracy skills, because children with lower mathematical language skills would not have had access to mathematical instruction in schools because they did not understand the language used to address these concepts (Purpura et al., 2019). Early knowledge of numbers had a direct influence on the arithmetic ability development. In order to facilitate it, Östergren and Träff (2013) research findings also stress the importance of training early number awareness before school entry.

Counting activities in early-childhood classes is often wrong in applying concepts, educators prioritize the ability to name numbers, not introduce the concept of how many objects are in the symbol. This common mistake is also made by parents at home, teaching how to spell names from one to ten, without explaining how many objects are in the names of the numbers one through ten. Papadakis et al., (2018) has provided an alternative to numeracy learning through experiments with the findings supporting that the use of digital devices such as tablets can make a significant contribution to understanding numbers by early-childhood students.

It is critical to broaden our understanding of the relationship between number talk and mathrelated activities, including how number talk takes place within and outside the context of mathrelated activities, to understand how these variables might facilitate math learning for children (Thippana et al., 2020). In the home numeracy climate, survey tests also correlated with math skills.

\subsection{Early Childhood Movement and Song}

Music / songs are an important part of human life. Useful for living with joy and well-being, it is very interesting to analyze various research studies related to music and children's brain development. Assuming studies regarding the importance of music and children's brain development can be established. One of them is the research Sarkar and Biswas (2015), an effort to access creative parts of the brain through dance, early childhood can more easily mathematical concepts such as spatial awareness and mathematical knowledge before formal assessments in elementary school. At a basic level, when students have access to pre-school mathematics learning through the performing arts, they are more than one month earlier than their non-Preschool peers when they Kindergarten classes (Ludwig et al., 2016).

Learning integrated mathematics with art engages both hemispheres of the brain and all types of students by preparing students with basic knowledge in mathematics before facing formal math concepts in Kindergarten ((Temple et al., 2020). Introducing music to children's lives means developing concentration, memory and listening skills. Singing songs helps children learn to speak patterns. Singing songs can also develop a vocabulary, and if you incorporate dance into it, your child can memorize words through movement. Music activates new brain neural pathways and ties that speed up the process of learning. This means increasing creativity and curiosity in children (Upadhyaya, 2017).

When children sing, children listen carefully to learn new lyrics and rhymes, children internalize word expressions, predict chorus, and mentally adjust rhythmic patterns (Winter \& Seeger, 2015) The movements and songs are very attractive to children, so a motivational effect on practicing can be anticipated. Integration in the educational process can motivate students to learn, create interesting needs from learning, and facilitate the learning process (Kołodziejski et al., 2014). Movement with music is considered to be the main in the five forms of music education. It is also described as an expression of movement or elements of dance. Gesture expressions should be accented and used especially during preschool and early school age. Buchoff (2015) 
said that movement and song activities are one of the elements commonly used in the teaching and learning process in preschool. The use of elements of music and movement helps to attract children's attention and focus, increase understanding and enrich children's emotional and behavioral development. Preschool teachers should vary their teaching approach to include the use of music and movement in their mathematics learning. As a result, music and movement are seen as useful, including helping to attract children's attention and interest, increasing children's understanding and building children's emotional development.

Globalization and the process of internationalization led to the separation of isolationism for centuries. Society is becoming highly diverse culturally. Educating citizens capable of leading active and effective lives in culturally diverse environments is one of the most pressing challenges. Early childhood begins to recognize ethnic / racial diversity. There are currently many bodies of research that address the ages and stages in developing an understanding of the race and ethnicity of children. Research shows that the attitudes of a child towards their own race, and towards other racial groups begin to form in the preschool years. Therefore, multicultural education must start with the very young (Logvinova, 2016; Lopintsova et al., 2012). Research and development of learning media for children's songs use distinctive patterns or traditional musical idioms (Nketia, 1982; Phyfferoen, 2019; Tsai, 2017). It is inspired by one of the most influential Taiwanese composers, Hsiao (1999), whose music is a blend of traditional Taiwanese musical idioms and Western musical composition techniques. The purpose of using these musical mixes is to promote these works as valuable pedagogical material. The dominant brain activity occurred when the subject listened to familiar music in the temporal lobe and when the subject listened to new music in the frontal lobe (Wardani et al., 2018).

\section{METHOD}

This research and development are a research method that combines quantitative and qualitative research methods that are packaged with certain stages in the context of a feasibility test or a test of the effectiveness of a product developed / innovated or a new / original product related to the education sector. Qualitative approach is carried observation activities and anecdotal notes, which are useful for describing events that have occurred while the research is ongoing. The quantitative approach is carried out through the observation guidelines used to calculate the level of effectiveness of learning media (Gelantram) in introducing early mathematics concept for children aged 4-5 years.

In conducting research and development, researchers use the ADDIE model design (Analysis, Design, Development or Production, Implementation or Delivery, Evaluation). This research and development model aim to produce a movement and songs learning media to improve early math skills. ADDIE Model uses five simple steps, including Analysis, Design, Development or Production, Implementation or Delivery, Evaluation. However, this model provides clear and standard detailed procedural steps for the media's feasibility and needs. Learning Media are expected to be used as a whole in the world of early-childhood education, but with the conditions that must be passed through several tests of feasibility extensively by using a larger number of samples and different sample strata so that people from various circles can be used.

\subsection{Validation and Media Effectiveness Test}

\subsubsection{Validation Test}

The model trial procedure in stages through a process of testing experts (one to one), smallgroup trials, large-group trials and the media effectiveness test (field try-out). Each trial was evaluated for the improvement of the media developed to revise the final product. Expert validity tests are carried out on learning media to determine the quality and effectiveness of the product being developed. Product design assessments are doing by experts in the fields of early-childhood education, dance and music, language, and media to obtain statements about the practicality and suitability of learning media (Gelantram). 


\subsection{Media Effectiveness Test}

\subsubsection{Instrument}

The instrument on the media effectiveness test uses indicators of aspects of the development of the 2013 ECE Indonesian curriculum.

Table 1. Early Mathematical Instruments

\begin{tabular}{|c|c|}
\hline $\begin{array}{l}\text { Mathematics } \\
\text { Ability Variable }\end{array}$ & Aspects of Early Mathematical Understanding \\
\hline Geometry & a. Recognize the shape of a circle, triangle, square and rectangle \\
\hline & $\begin{array}{l}\text { b. Matching geometric shapes to concepts with geometric shapes on real objects } \\
\text { c. Mention geometric forms }\end{array}$ \\
\hline Measurement & $\begin{array}{l}\text { a. Comparing the concept, long-short, high-low, large-small } \\
\text { b. Measuring Length-short, high-low, large-small }\end{array}$ \\
\hline & c. Estimating Length-short, high-low, large-small \\
\hline Number & $\begin{array}{l}\text { a. Understand the concept of numbers 1-10 } \\
\text { b. Associating numbers (sums) with numbers is called a one-to-one } \\
\text { correspondence } \\
\text { c. Number sequence system }\end{array}$ \\
\hline
\end{tabular}

\subsubsection{Data Collection}

Data collection techniques are carried out with several kinds of techniques: (1) Interview conducted during the need's analysis as well as in the media revision process to collect input and suggestions in the development of the designed media; (2) Observation carried out starting from activities when taking data for need's analysis as well as on testing the use of the media; (3) Documentation conducted to document research results in various forms of photo and video recordings during the research trial process.(4) Field notes, are notes made by the researcher to record various things during the research needed to find accurate information as input in research and development media (Gelantram).

\subsubsection{Analysis Data of Media Effectiveness Test}

Data analysis in research and development of Learning Media (Gelantram) uses two types of

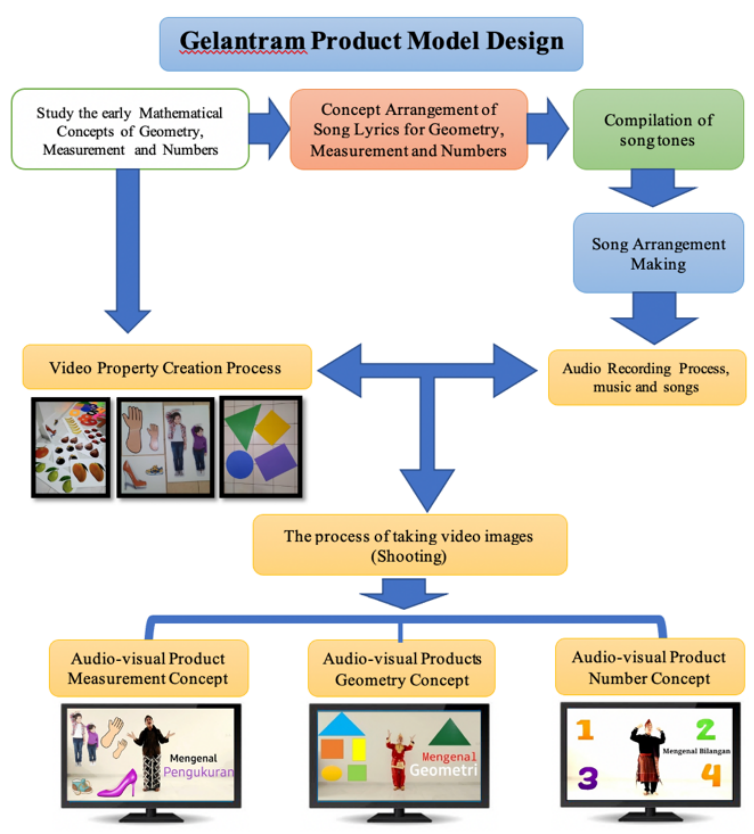
data. The qualitative data were analyzed using transcripts of field notes and observations and interpreted in a descriptive narrative. The quantitative data generated from the calculation of the test results from data before, and after the uses of the Media (Gelantram) in the field trial activities were analyzed through the SPPS program with gain score statistics.

\subsection{Gelantram Product Model Design}

The design of the learning media model for the Idiom Song of Traditional Mathematical Music (Gelantram), which will determine the criteria for the quality of the model which includes validity, practicality, and the effectiveness of the model (see figure 1).

Figure 1. Product Model Design 


\subsubsection{Gelantram media conceptual model}

The concept design in the preparation of Gelantram media can be seen in figure 4, which shows the media concept starting from the analysis of media needs in early childhood mathematics learning carried out in a preliminary study. Then proceed with a literature study to find suitable media to improve early childhood math skills. Researchers designed a media concept design based on these results and collaborated with music and dance education experts for children, researchers created the Gelantram media.

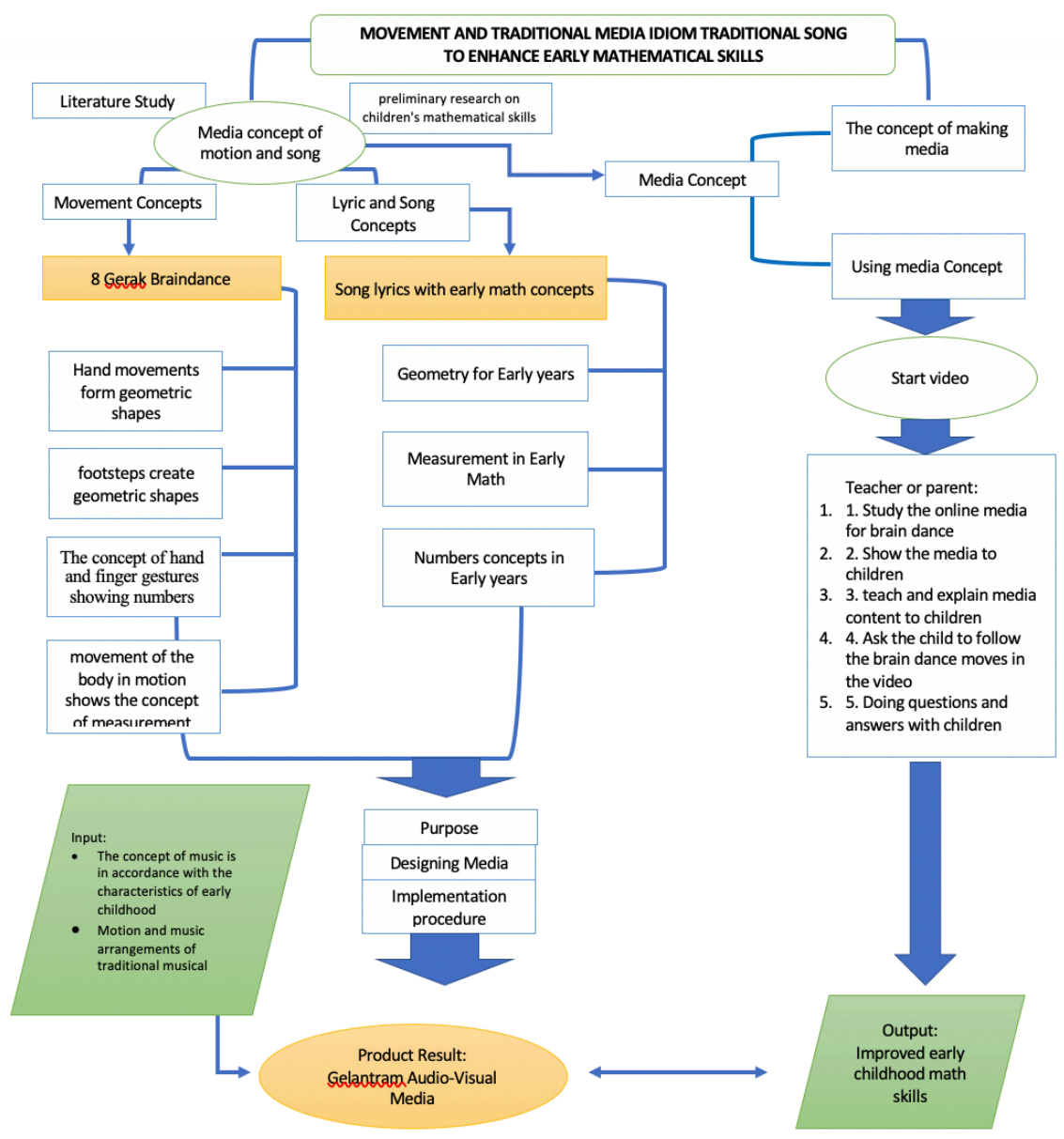

Figure 2. Conceptual Model

\section{RESULT AND DISCUSSION}

\subsubsection{Preliminary Observation Data}

Data collection activities in the preliminary study, it was carried out using conversation and question and answer methods, in this case the researcher invited teachers to hold an observation Focus Group Discussion (FGD) with thirty early-childhood teachers in Jakarta. Teachers are asked to answer difficulties in the introduction of early mathematics concepts, especially in children aged 3-4 years, about three basics of early mathematics, geometry, measurement and numbers. The results of needs analysis data that show an understanding of early mathematics in early childhood, especially in children aged 3-4 years about geometry, measurement and numbers. Can be illustrated in the graphic form (see figure 3-5).

The percentage graph image in figure 3, represents an understanding of early mathematics, especially geometry in the initial activities for observations for need's analysis. The teachers stated that the children still had difficulty distinguishing geometric shapes, be it triangles, circles (round) 


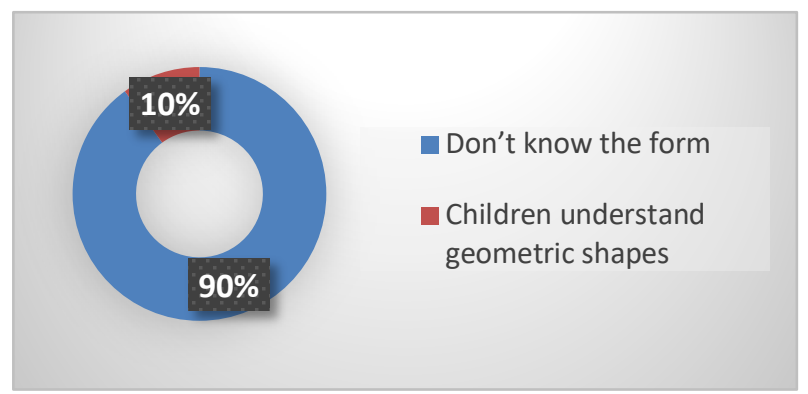

squares, and rectangles. Data obtained from the recognition of teachers in schools of several children. Amount $90 \%$ children cannot mention geometry shapes yet. About $10 \%$ of kids can name some shape from Geometry, and those're only two of some geometric shapes.

Figure 3. children aged 4-5 years knowledge about geometry

The number $85 \%$ in figure 4 , is for the ability to recognize the number of symbols without $u$ nderstanding the concept ofthe number. The teachers stated that children still had difficulty rec ognizing numbers, be it sorting numbers anddistinguishing the number of numbers. And the tea cher also provided information that children had difficulty recognizingnumbers. Numbers, child ren can only sound like the numbers one to ten but do not know the number of objects.

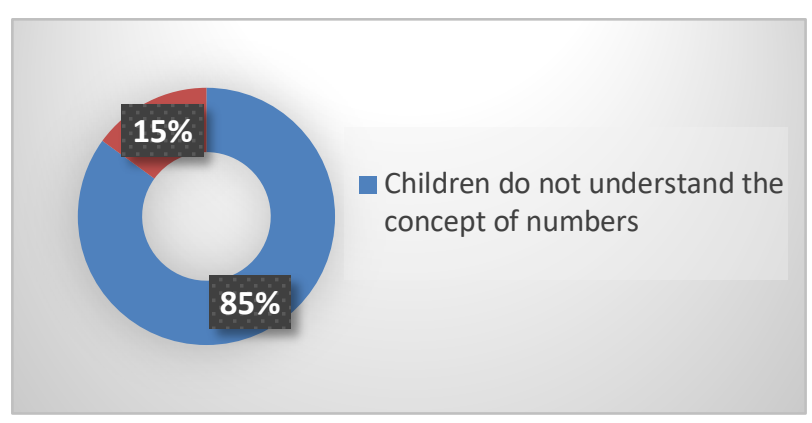

Figure 4. children aged 4-5 years knowledge about numbers

Figure 5 show about the teachers answered that children at the age of 4-5 years, had difficulty getting to know the concept of measurement. Children were still difficult to distinguish LengthShort, Big-Small and High-Low. Based on the results of interviews with teachers in the role of schools in introducing early mathematics concepts, a little is still constrained by the limitations of the media used for children to be more enthusiastic about learning.

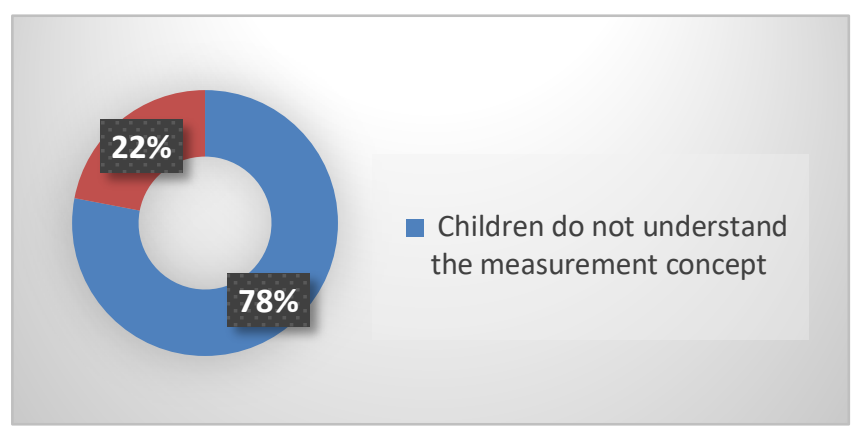

Figure 5. children aged 4-5 years knowledge about Measurement

\subsubsection{Expert Validation}

An expert in early childhood education movement who is an expert in movement media and traditional mathematics songs is an expert who works as a lecturer in the Faculty of Education of the Early Childhood Education study program at the State University of Jakarta. Music experts who assess music content on Motion media and traditional mathematics songs (Gelantram), to see whether the music content on the Gelantram media is appropriate to music at an early age, both the suitability of the music tempo, the suitability of content / material or song lyrics in early childhood. Based on the media eligibility criteria above, the percentage results of the feasibility test of all experts can be seen in table 2. 
Table 2. Result of Theoretical Feasibility Test (Expert Test)

\begin{tabular}{|c|c|c|c|c|}
\hline No & Expert & Value & Percentage & Media Feasibility Value \\
\hline 1 & Media & $23 / 24 \quad x 100 \%$ & $95,83 \%$ & Excellent \\
\hline 2 & Early Childhood & $20 / 20 \times 100 \%$ & $100 \%$ & Excellent \\
\hline 3 & Movement & $15 / 16 \times 100 \%$ & $93,75 \%$ & Excellent \\
\hline 4 & Music & $16 / 16 \times 100 \%$ & $100 \%$ & Excellent \\
\hline
\end{tabular}

\subsubsection{Empirical Test Result}

Next, to complete the theoretical feasibility test, the feasibility test through empirical tests was carried out on Motion Media and traditional mathematics songs. The empirical test for the movement media and traditional mathematics songs involved several respondents from the city of South Jakarta. The empirical test is a feasibility test for the media of motion and traditional mathematics songs for media users, namely children aged 3-4 years (geometry see on table 3; measurement concept see on figure 6; and about number see on figure 7).

Table 3. Small Group Geometry Concept Trial Results (pre-test and post-test)

\begin{tabular}{|c|c|c|c|c|c|c|c|}
\hline \multirow[t]{2}{*}{$\begin{array}{l}\text { Respond- } \\
\text { ent }\end{array}$} & \multicolumn{2}{|c|}{$\begin{array}{l}\text { Recognize the shape of a } \\
\text { circle, triangle, square and } \\
\text { rectangle }\end{array}$} & \multicolumn{2}{|c|}{$\begin{array}{c}\text { Matching geometric } \\
\text { shapes to concepts with } \\
\text { geometric shapes on real } \\
\text { objects }\end{array}$} & \multicolumn{2}{|c|}{$\begin{array}{l}\text { State the forms of } \\
\text { geometry }\end{array}$} & \multirow[t]{2}{*}{ Average } \\
\hline & pre-test a & post-test a & $\begin{array}{l}\text { pre-test } \\
\text { b }\end{array}$ & $\begin{array}{c}\text { post-test } \\
\mathrm{b}\end{array}$ & $\begin{array}{c}\text { pre-test } \\
\text { c }\end{array}$ & $\begin{array}{c}\text { post-test } \\
\mathrm{c} \\
\end{array}$ & \\
\hline $\mathrm{R} 1$ & $75 \%$ & $100 \%$ & $75 \%$ & $100 \%$ & $25 \%$ & $100 \%$ & $42 \%$ \\
\hline $\mathrm{R} 2$ & $75 \%$ & $100 \%$ & $75 \%$ & $100 \%$ & $25 \%$ & $100 \%$ & $42 \%$ \\
\hline R3 & $50 \%$ & $100 \%$ & $25 \%$ & $100 \%$ & $25 \%$ & $100 \%$ & $67 \%$ \\
\hline $\mathrm{R} 4$ & $25 \%$ & $100 \%$ & $25 \%$ & $100 \%$ & $25 \%$ & $100 \%$ & $75 \%$ \\
\hline R5 & $50 \%$ & $100 \%$ & $50 \%$ & $100 \%$ & $50 \%$ & $100 \%$ & $50 \%$ \\
\hline
\end{tabular}

At the beginning of the media effectiveness experiment, children were asked about three early math concepts. Results of the questions and answers at the beginning of the activity showed the same results as the results of the preliminary study for need's analysis. $80 \%$ of the five respondents did not understand the three basic concepts of early mathematics, namely geometry (see pre-test geometry on table 3), measurement (see figure 6) and numbers (see figure 7). Then the next activity the children were given special learning by using the media for math learning. Children are invited to participate to follow the movements and songs of the Idiom Traditional Music mathematics while getting to know geometry, measurements and numbers with audio-visual learning media, for several weeks.

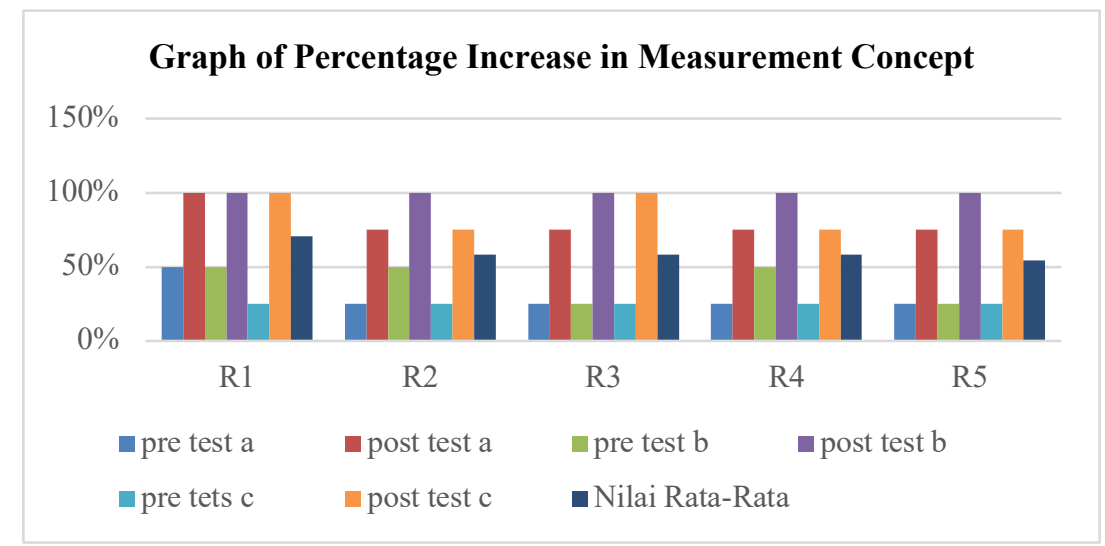

Figure 6. Results of Small Group Measurement Concept Trial (pre-test and post-test) 


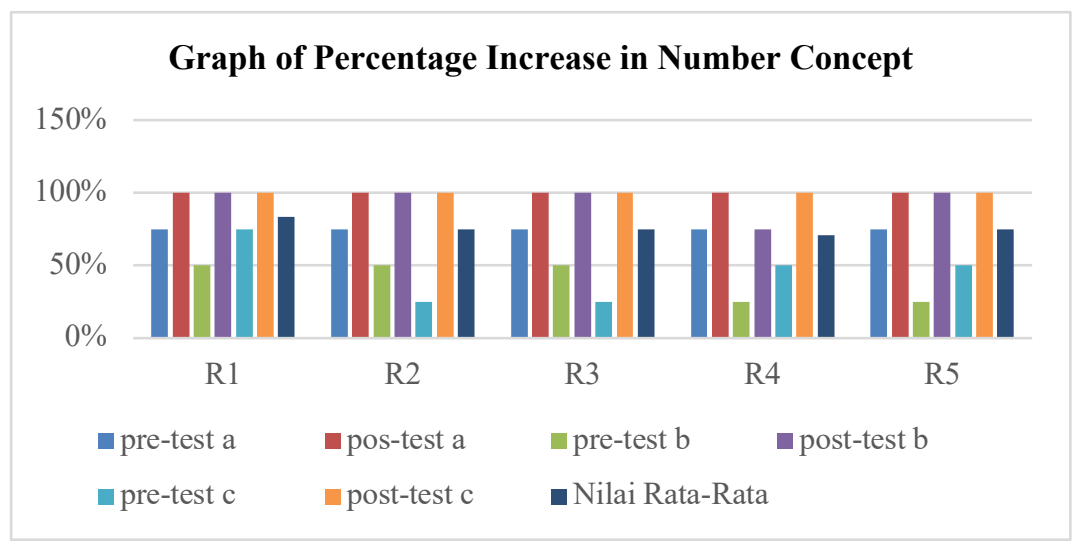

Figure 7. Graph of the Increase in Value Concept of Numbers

Based on the results of the effectiveness test through pre-test and post-test on five respondents at one research location, it can be concluded that there is a significant increase in the acquisition of values for early mathematical understanding, especially geometry, numbers and measurements. This can be seen from the scores obtained before the test and after the test. As illustrated in the chart above, the results of the effectiveness test form the final basis for revision and complement the shortcomings of Media Gelantram.

\subsection{Discussion}

The findings in research and development of Gelantram media for early-childhood education begin with preliminary research, which is the result of a field needs analysis in early-childhood mathematics education. The average ability of Indonesian children in math concepts is still low in the world competitive level (PISA worldwide ranking; Indonesia's PISA results show need to use education resources more efficiently, 2016). The results of field observations in several kindergartens to test the initial mathematical abilities have shown that there is still a need for media that can help teachers improve children's early math abilities. Likewise, the results of the preliminary analysis in the form of focus group discussions with kindergarten teachers, the result is that there is so much demand for instructional media related to how to improve early-childhood mathematics education. Moreover, media in the form of motion arts and songs with elements or goals to improve early mathematics skills are few in the field of early-childhood education. Based on the results of the field needs analysis, the researchers designed and produced instructional media with material content to improve the concept of early math abilities of children aged 4-5 years.

\subsubsection{Findings on the Improvement of Early Mathematical Ability in Geometry}

Currently, researchers still limit the initial mathematical concepts to only three types of mathematical concepts for children, namely geometry, measurement, and numbers. Researchers chose the concept of early geometry math skills based on the importance of the concept of geometry for children according to Clements (2014) that geometry and spatial reasoning are important because these concepts form the basis of learning mathematics and other subjects. Teachers at an advanced-level use geometric models for arithmetic when using grids to describe multiplication or circles or bars to describe fractions. Furthermore, based on recent research by Clements et al., (2019) which found that early-childhood form's schemas based on analysis of visual form features. As children develop, children continue to rely primarily on visual matching to differentiate geometric shapes. The child is also able to recognize the components and simple properties of familiar geometric shapes.

Based on the results of this study, the researcher tried to introduce geometric shapes in learning media related to the introduction of the concept of geometry. The findings in the field on expert due diligence data for geometry concept videos have been declared very feasible by early-childhood experts in shaping children's early math concepts. Likewise, the small-group trial data given to five early-childhood respondents showed a $95 \%$ increase in the scores on the pre-test and posttest data in understanding the concept of geometric shapes. In line with a recent study conducted 
by Paul (2019) who said, there is a lot more in the relationship between mathematics and music. Just as, there is more to this analogy between math and music score, this analogy is more pleasing to mathematicians than to musicians.

An important finding in the field observation notes from collaborator teachers is that the $G e$ lantram learning media with traditional idiom's music Mans (2002) has brought new knowledge for children to get to know the national culture apart from Minang culture (West Sumatra) in the geometry concept video. In addition to improving early math skills, the advantages of traditional music are also able to build children's cultural characters (Kristanto, 2020; Nyota \& Mapara, 2008). Research and development of learning media for children's songs uses distinctive styles or traditional musical idioms (Nketia, 1982; Phyfferoen, 2019; Tsai, 2017). It is inspired by one of the most influential Taiwan composers namely Hsiao (1999), the music is a blend of traditional Taiwanese musical idioms and Western musical composition techniques. The purpose of using these musical mixes is to promote these works as valuable pedagogical material.

\subsubsection{Findings on the Improvement of Early Mathematics Ability to Measurement}

The results of the Media expert's assessment on the three Gelantram videos that raised the concepts of geometry, measurement, and numbers stated that $93.75 \%$ were very suitable to be used as learning media for children 4-5 years. From the level of the flow of media content, material content, media safety, and others, this learning media is interesting to be disseminated to various related parties so that it can help the process of increasing understanding of early mathematical concepts, especially in the ability of measurement concepts, this media is very effective for children.

Likewise, according to the results of expert tests on music and dance movements, the suitability of the motion and music in this video was declared very feasible. PAUD experts assess that the concept of early mathematics measurement on the video gelantram is very appropriate in earlychildhood education standards and attractive as a learning medium who is preferred by children. How these movements and songs become interesting media for children. Researchers look at the facts of a recent study of music to improve early math concepts.

Music, movement and song training, is considered a multi-sensory program that simultaneously integrates the visual, audio, oral and kinesthetic senses. In addition, motion learning media and songs stimulate cognitive function in a ludic way instead of directly utilizing the context of traditional school learning, including mathematics. The main finding of Ribeiro snd Santos (2020) is that intervention in understanding mathematical concepts by involving motion and song / music appears to be a useful tool for improving various conceptual understanding of early mathematical skills, such as measurement.

The Gelantram video introduces the concept of early mathematics measurement using the idiom of traditional Javanese music. The important finding in this section is that the effect of multidisciplinary science in this study has improved other aspects of child development, especially aspects of understanding on multicultural education. The child in the video gelantram with this initial mathematical concept of measurement makes the child understand the existence of various cultures in Indonesia through the traditional clothes worn in the video. The child gets to know Javanese culture, and the types of traditional Javanese music.

An $85 \%$ increase in scores on the pre-test and post-test data on early math abilities on the measurement concept, shows that the video gelantram learning media shows the effectiveness of the media that is suitable as a reference in improving children's early math skills. It can be seen from the results of the teacher's field notes. The children's enthusiasm for music and dancing makes it easier for children to absorb and memorize measurement concepts contained in the video gelantram material, which introduces the concepts, big-small, long-short, high-low. Children are also helped by visualizing the concepts shown in the video, so that children are able to recognize the concept of measurement in a relatively short time. This shows the effectiveness of the media in introducing the initial mathematical concept of measurement at the pre-school level. 


\subsubsection{Findings on the Improvement of Initial Math Ability in Numbers}

The Recent research supporting the development of motion learning media and chanting songs show that the impact of preschool mathematics learning media on children's early mathematics learning, which shows positive children's outcomes, is at the heart of high-quality preschool. The study Wakabayashi et al., (2020) examined the effect of adding mathematics learning media on the widely used comprehensive children's curriculum with the newly developed skills-based curriculum. The findings indicate the feasibility of implementation. In addition, it could improve children's math knowledge and skills during the preschool year and found additional positive effects on the results of children's early math skills. Likewise, the research of Austin et al., (2011) extends the existing research relative to predictors of early math skills. Teaching math as often as literacy skills might reinforce the more efficient acquisition of the two. Research suggests that some differential training in early-childhood education institutions is so that educational institutions are able to design various learning activities to improve children's early math skills by using appropriate learning media.

Gelantram video with the concept of numbers, introducing the culture of the archipelago from the North Sumatra region. This Gelantram learning media product introduces North Sumatra traditional clothes and the idiom of traditional music that has been adapted to the characteristics of early-childhood music. So that the assessment of music experts on all Gelantram videos is declared very feasible, because even though it uses the idiom traditional music, the color of the music has been modified by researchers so that the music is successful and effective in attracting children's interests. The hope of researchers in making learning media is that it is easier for teachers to improve early-childhood math skills, as well as being able to introduce the rich diversity of Indonesian cultures and provide multicultural learning in early childhood through idiom traditional music.

\section{CONCLUSION}

Based on the results of research and discussion that have been described, the following conclusions, implementation and suggestions are formulated. The findings of research and development of Gelantram media are developed through the initial process of preliminary studies, literature reviews, literature studies, and observations and interviews. It finds that teachers or adults around children aged 4-5 years do not have much appropriate media to improve early-childhood math skills. Early-childhood interest problems in mathematics get solutions to problems through the use of learning media Gelantram. Based on the results of the small-group test, the development of gelantram learning media is proven to be effective in improving early mathematics skills in children aged 4-5 years in the city of South Jakarta. The form of Gelantram media is soft motion video files and songs for gadgets such as smart phones, laptops, tablets, or desktop computers. Based on the points of the research findings, it can be concluded that the learning media $\mathrm{Ge}$ lantram can improve the early math skills of children aged 4-5 years. Learning media, Gelantram is media that are designed and developed to improve understanding of early-childhood math skills. Gelantram media can be used for the needs of learning media to improve early math skills in schools. It can also be used as a solution to the problem of increasing children's mathematics interest by parents at home.

\section{REFERENCES}

An, S. A., \& Tillman, D. A. (2015). Music activities as a meaningful context for teaching elementary students mathematics: a quasi-experiment time series design with random assigned control group. European Journal of Science and Mathematics Education, 3(1), 4560. https://doi.org/10.1038/srep15999

An, S., Capraro, M. M., \& Tillman, D. A. (2013). Elementary Teachers Integrate Music Activities into Regular Mathematics Lessons: Effects on Students' Mathematical Abilities. Journal for Learning through the Arts: A Research Journal on Arts Integration in Schools and Communities, 9(1). https://doi.org/10.21977/d99112867 
Austin, A. M. B., Blevins-Knabe, B., Ota, C., Rowe, T., \& Lindauer, S. L. K. (2011). Mediators of preschoolers' early mathematics concepts. Early Child Development and Care, 181(9), 1181-1198. https://doi.org/10.1080/03004430.2010.520711

Barrett, J. E., Cullen, C., Sarama, J., Miller, A. L., \& Rumsey, C. (2011). Children's unit concepts in measurement: a teaching experiment spanning grades 2 through 5. 637-650. https://doi.org/10.1007/s11858-011-0368-8

Basco, R. O. (2020). Effectiveness of Song, Drill and Game Strategy in Improving Mathematical Performance. International Educational Research, 3(2), p1. https://doi.org/10.30560/ier.v3n2p1

Bausela Herreras, E. (2017). Risk low math performance PISA 2012: Impact of assistance to Early Childhood Education and other possible cognitive variables. Acta de Investigación Psicológica, 7(1), 2606-2617. https://doi.org/10.1016/j.aipprr.2017.02.001

Buchoff, R. (2015). Childhood Education. January. https://doi.org/10.1080/00094056.1995.10521830

Clements, D. H. (2014). Geometric and Spatial Thinking in Young Children. In Science of Advanced Materials (Vol. 6, Issue 4). National Science Foundation. https://doi.org/10.1166/sam.2014.1766

Clements, D. H., Baroody, A. J., Joswick, C., \& Wolfe, C. B. (2019). Evaluating the Efficacy of a Learning Trajectory for Early Shape Composition. XX(X), 1-22. https://doi.org/10.3102/0002831219842788

Clements, D. H., Swaminathan, S., Anne, M., \& Hannibal, Z. (2016). Young Children 's Concepts of Shape. 30(2), 192-212.

Cross, C. T., Woods, T., \& Schweingruber, H. (2009). Mathematics Learning in Early Chidhood Paths Toward Excellence and Equity. The National Academies Press.

Geary, D. C. (2011). Cognitive predictors of achievement growth in mathematics: A 5-year longitudinal study. Developmental Psychology, 47(6), 1539-1552. https://doi.org/10.1037/a0025510

Geary, D. C. (2012). Learning Disabilities and Persistent Low Achievement in Mathematics. $J$ Dev Behav Pediatr., 32(3), 250-263. https://doi.org/10.1097/DBP.0b013e318209edef.Consequences

Gejard, G., \& Melander, H. (2018). Mathematizing in preschool: children 's participation in geometrical discourse. 1807. https://doi.org/10.1080/1350293X.2018.1487143

Harususilo, Y. E. (2020). Skor PISA Terbaru Indonesia, Ini 5 PR Besar Pendidikan pada Era Nadiem Makarim. https://pusmenjar.kemdikbud.go.id/

Hsiao, T. (1999). Romanticism with Deep Affection: Selected Articles About the Music of Hsiao Tyzen (Hengzhe Lin (ed.)). Wang Chun Feng Wen Hua Fa Xing.

Kasuya-Ueba, Y., Zhao, S., \& Toichi, M. (2020). The Effect of Music Intervention on Attention in Children: Experimental Evidence. Frontiers in Neuroscience, 14(July), 1-15. https://doi.org/10.3389/fnins.2020.00757

Kołodziejski, M., Králová, P. D. E., \& Hudáková, P. D. J. (2014). Music and Movement Activities and Their Impact on Musicality and Healthy Development of a Child. Journal of Educational Revies, 7(4).

Kristanto, W. (2020). Javanese Traditional Songs for Early Childhood Character Education. 14(1), 169-184.

Litkowski, E. C., Duncan, R. J., Logan, J. A. R., \& Purpura, D. J. (2020). When do preschoolers 
learn specific mathematics skills? Mapping the development of early numeracy knowledge. Journal of Experimental Child Psychology, 195, 104846. https://doi.org/10.1016/j.jecp.2020.104846

Logvinova, O. K. (2016). Socio-pedagogical approach to multicultural education at preschool. Procedia - Social and Behavioral Sciences, 233(May), 206-210. https://doi.org/10.1016/j.sbspro.2016.10.203

Lopintsova, O., Paloniemi, K., \& Wahlroos, K. (2012). Multicultural Education through Expressive Methods in Early Childhood Education.

Ludwig, M. ., Marklein, M. ., \& Song, M. (2016). Arts Integration: A Promising Approach to Improving Early Learning. American Institutes for Research.

Macdonald, A., \& Lowrie, T. (2011). Developing measurement concepts within context : Children 's representations of length. 27-42. https://doi.org/10.1007/s13394-011-0002-7

Mans, M. (2002). Playing The Music- Comparing Perfomance of Children's Song and dance in Traditional and Contemporary Namibian Education. In The Arts in Children's Live (pp. 7186). Kluwer Academic Publishers.

Maričić, S. M., \& Stamatović, J. D. (2017). The Effect of Preschool Mathematics Education in Development of Geometry Concepts in Children. 8223(9), 6175-6187. https://doi.org/10.12973/eurasia.2017.01057a

Missall, K., Hojnoski, R. L., Caskie, G. I. L., \& Repasky, P. (2015). Home Numeracy Environments of Preschoolers: Examining Relations Among Mathematical Activities, Parent Mathematical Beliefs, and Early Mathematical Skills. Early Education and Development, 26(3), 356-376. https://doi.org/10.1080/10409289.2015.968243

Moreno, S., Bialystok, E., Barac, R., Schellenberg, E. G., Cepeda, N. J., \& Chau, T. (2011). Shortterm music training enhances verbal intelligence and executive function. Psychological Science, 22(11), 1425-1433. https://doi.org/10.1177/0956797611416999

Nketia, J. H. K. (1982). Developing Contemporary Idioms out of Traditional Music. Studia Musicologica Academiae Scientiarum Hungaricae, 24, 81. https://doi.org/10.2307/902027

Nyota, S., \& Mapara, J. (2008). Shona Traditional Children' s Games and Play: Songs as Indigenous Ways of Knowing. English, 2(4), 189-203.

Östergren, R., \& Träff, U. (2013). Early number knowledge and cognitive ability affect early arithmetic ability. Journal of Experimental Child Psychology, 115(3), 405-421. https://doi.org/10.1016/j.jecp.2013.03.007

Pantoja, N., Schaeffer, M. W., Rozek, C. S., Beilock, S. L., \& Levine, S. C. (2020). Children's Math Anxiety Predicts Their Math Achievement Over and Above a Key Foundational Math Skill. Journal of Cognition and Development, 00(00), 1-20. https://doi.org/10.1080/15248372.2020.1832098

Papadakis, Stamatios, Kalogiannakis, M., \& Zaranis, N. (2017). Improving Mathematics Teaching in Kindergarten with Realistic Mathematical Education. Early Childhood Education Journal, 45(3), 369-378. https://doi.org/10.1007/s10643-015-0768-4

Papadakis, Stamatios, Kalogiannakis, M., \& Zaranis, N. (2018). The effectiveness of computer and tablet assisted intervention in early childhood students' understanding of numbers. An empirical study conducted in Greece. Education and Information Technologies, 23(5), 1849-1871. https://doi.org/10.1007/s10639-018-9693-7

Papadakis, Stamatis, Kalogiannakis, M., \& Zaranis, N. (2016). Comparing Tablets and PCs in teaching Mathematics: An attempt to improve Mathematics Competence in Early Childhood Education. Preschool and Primary Education, 4(2), 241. https://doi.org/10.12681/ppej.8779 
Paul, T. (2019). Mathematics and music: loves and fights To cite this version.

PISA worldwide ranking; Indonesia's PISA results show need to use education resources more efficiently, (2016).

Phyfferoen, D. (2019). The Dagbon Hiplife Zone in Northern Ghana Contemporary Idioms of Music Making in Tamale. 1(2), 81-104.

Purpura, D. J., Napoli, A. R., \& King, Y. (2019). Development of Mathematical Language in Preschool and Its Role in Learning Numeracy Skills. In Cognitive Foundations for Improving Mathematical Learning (1st ed., Vol. 5). Elsevier Inc. https://doi.org/10.1016/b978-0-12-815952-1.00007-4

Ribeiro, F. S., \& Santos, F. H. (2020). Persistent Effects of Musical Training on Mathematical Skills of Children With Developmental Dyscalculia. Frontiers in Psychology, 10(January), 1-15. https://doi.org/10.3389/fpsyg.2019.02888

Roa, R., \& IA, C. (2020). Learning Music and Math, Together as One: Towards a Collaborative Approach for Practicing Math Skills with Music. In I. T. (eds) Nolte A., Alvarez C., Hishiyama R., Chounta IA., Rodríguez-Triana M. (Ed.), Collaboration Technologies and Social Computing. Col (Vol. 26, Issue 5, pp. 659-669). https://doi.org/https://doi.org/10.1007/978-3-030-58157-2_10

Sarama, J., \& Clements, D. H. (2006a). Mathematics, Young Students, and Computers: Software, Teaching Strategies and Professional Development. The Mathematics Educato, 9(2), 112134.

Sarama, J., \& Clements, D. H. (2006b). Mathematics in early childhood. International Journal of Early Childhood, 38(1). https://doi.org/10.1007/bf03165980

Sarkar, J., \& Biswas, U. (2015). The role of music and the brain development of children. 4(8), $107-111$.

Sheridan, K. M., Banzer, D., Pradzinski, A., \& Wen, X. (2020). Early Math Professional Development: Meeting the Challenge Through Online Learning. Early Childhood Education Journal, 48(2), 223-231. https://doi.org/10.1007/s10643-019-00992-y

Silver, A. M., Elliott, L., \& Libertus, M. E. (2021). When beliefs matter most: Examining children's math achievement in the context of parental math anxiety. Journal of Experimental Child Psychology, 201, 104992. https://doi.org/10.1016/j.jecp.2020.104992

Sterner, G., Wolff, U., \& Helenius, O. (2020). Reasoning about Representations: Effects of an Early Math Intervention. Scandinavian Journal of Educational Research, 64(5), 782-800. https://doi.org/10.1080/00313831.2019.1600579

Temple, B. A., Bentley, K., Pugalee, D. K., Blundell, N., \& Pereyra, C. M. (2020). Using dance \& movement to enhance spatial awareness learning. Athens Journal of Education, 7(2), 153167. https://doi.org/10.30958/aje.7-2-2

Thippana, J., Elliott, L., Gehman, S., Libertus, K., \& Libertus, M. E. (2020). Parents' use of number talk with young children: Comparing methods, family factors, activity contexts, and relations to math skills. Early Childhood Research Quarterly, 53, 249-259. https://doi.org/10.1016/j.ecresq.2020.05.002

Tsai, Y. (2017). Taiwanese Traditional Musical Idioms Meet Western Music Composition: An Analytical and Pedagogical Approach to Solo Piano Works by Tyzen Hsiao. http://aquila.usm.edu/dissertations/1398

Upadhyaya, D. (2017). Benefits of Music and Movement in young children. Furtados School of Music. https://www.linkedin.com/pulse/benefits-music-movement-young-children-dhariniupadhyaya 
Vennberg, H., Norqvist, M., Bergqvist, E., Österholm, M., Granberg, C., \& Sumpter, L. (2018). Counting on: Long Term Effects of an Early Intervention Programme. 4, 355-362. http://urn.kb.se/resolve?urn=urn:nbn:se:umu:diva-148101

Verdine, B. N., Lucca, K. R., Golinkoff, R. M., Hirsh-, K., \& Newcombe, N. S. (2015). The Shape of Things: The Origin of Young Children's Knowledge of the Names and Properties of Geometric Forms. 8372(October). https://doi.org/10.1080/15248372.2015.1016610

Wakabayashi, T., Andrade-Adaniya, F., Schweinhart, L. J., Xiang, Z., Marshall, B. A., \& Markley, C. A. (2020). The impact of a supplementary preschool mathematics curriculum on children's early mathematics learning. Early Childhood Research Quarterly, 53, 329342. https://doi.org/10.1016/j.ecresq.2020.04.002

Wardani, I. K., Djohan, \& Sittiprapaporn, P. (2018). The difference of brain activities of musical listeners. 1st International ECTI Northern Section Conference on Electrical, Electronics, Computer and Telecommunications Engineering, ECTI-NCON 2018, 181-184. https://doi.org/10.1109/ECTI-NCON.2018.8378307

Winter, E., \& Seeger, P. (2015). The Important Role of Music in Early Childhood Learning. Independent School.

Zaranis, N., Kalogiannakis, M., \& Papadakis, S. (2013). Using Mobile Devices for Teaching Realistic Mathematics in Kindergarten Education. Creative Education, 04(07), 1-10. https://doi.org/10.4236/ce.2013.47a1001 